\title{
Regulación (legal) de la sexualidad. El ingreso de lo religioso en las intervenciones de oposición al matrimonio igualitario en el Parlamento argentino (2010)
}

MARÍA GANDELARIA SGRÓ RUATA*

\section{Resumen}

Tomando el debate sobre la ley de reforma del Código civil en Argentina (2010) que extiende el reconocimiento de la institución matrimonial a parejas sin distinción de sexos, este trabajo se propone indagar los sentidos conectados con lo religioso/ la religión en los discursos parlamentarios en oposición al proyecto de ley. A partir de las intervenciones en ambas cámaras legislativas (Diputados y Senadores nacionales) que conforman lo que denominamos campo de oposición parlamentaria, se plantean categorías para captar la emergencia de la dimensión religiosa en el debate parlamentario, en el momento en que el poder legislativo decide el futuro del proyecto de ley. Así, se busca poner en tensión los vínculos entre lo religioso y lo político cuando la sexualidad se vuelve un asunto de debate público.

Palabras clave: Matrimonio Igualitario. Iglesia Católica. Derechos Sexuales y Reproductivos. Cosmovisiones Religiosas. Espacio Público.

\footnotetext{
* Universidad Nacional de Córdoba, Argentina
} 


\title{
The (legal) regulation of sexuality. The religious in debates about same sex marriage in the Argentinian Parliament (2010)
}

\begin{abstract}
Taking the debates about the civil code reform bill in Argentina (2010), which extends the recognition of the matrimonial institution to same sex couples, this work proposes to investigate the religious senses incorporated in the parliamentary speeches opposing this change. From the speeches in both legislative chambers (nationals Deputies and Senators) that shapes what we name a field of parliamentary opposition, a set of categories are proposed to catch the emergency of the religious dimension in the parliamentary debate, when the legislative power decides the future of the reform bill. Thus, this work aims to put into tension the links between the religious and the political when the sexuality becomes a matter of public debate.
\end{abstract}

Keywords: Same sex marriage. Catholic church. Reproductive and sexual rights. Religious discourse. Public space.

\section{Introducción}

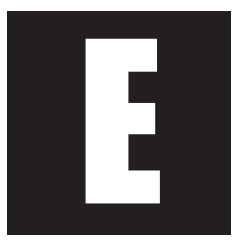

n diferentes países de América Latina, la sexualidad ha ingresado de manera creciente como tópico de discusión pública política, en especial por el avance en el terreno de derechos sexuales y reproductivos (Araujo, 2010). Las demandas a nivel legal han sido, en las últimas décadas, un ámbito privilegiado (aunque no el único) de las acciones llevadas adelante por los movimientos feministas y por la diversidad sexual en diferentes niveles (nacional, regional, internacional) (Pecheny; De la Dehesa, 2011). Pero las demandas por ampliación y reconocimiento de derechos ponen en escena, y es lo que interesa especialmente aquí, maneras de concebir la sexualidad demarcando, también, los límites que van 
definiendo (definen) lo legitimo, lo moral, lo normal. El cuestionamiento al orden de sentidos dado, vivido como norma natural (universal) vuelve visibles los procesos de constitución de ese orden como histórico y social o, en otras palabras, la sexualidad se revela como política (Fassin, 2009).

Familia y matrimonio, como órdenes simbólicos materializados en cuerpos legales, aparecen como significaciones sociales centrales en los discursos de impugnación y demandas de los movimientos, puesto que uno de sus propósitos principales es desnaturalizar las definiciones instituidas que consideran a la familia legal y legítima como producto de la unión heterosexual orientada a la reproducción biológica (Vaggione, 2008). Cuando el cuestionamiento emerge y el orden se disputa por la acción de diferentes sectores, prácticas en oposición se articulan también más o menos visiblemente en el espacio de lo público como maneras de intervenir en la política sexual contemporánea.

En Argentina, en el 2010, se sanciona la ley 26618 de reforma del código civil - conocida como ley de matrimonio igualitario - en un contexto signado por un intenso debate y movilización sociales. Más allá de los resultados de la votación, el debate se posiciona como un momento de observación privilegiado, porque inscribe como "posibilidad" la transformación legal, generando condiciones de participación en el espacio público y, en consecuencia, facilitando el acercamiento a los discursos puestos en circulación pública en oposición a la ley.

El debate sobre matrimonio entre personas del mismo sexo es uno de los tantos momentos en los que el orden sexual se vuelve visible, se hace objeto de disputas y en el campo de la sexualidad esta tensión trae a escena una dimensión que adquiere especial relevancia por su complejidad: la dimensión religiosa o de lo religioso.

Diversos estudios realizados en la región pusieron de relieve y dieron cuenta de la relevancia de la intervención de ciertos actores, en los 
procesos de politización de la sexualidad, que operan en defensa de un orden sexual heteronormativo, buscando incidir en el espacio de lo público; entre esos actores, la jerarquía de la iglesia católica es uno de los que adquiere principal consideración (Mejía, 2003; Dides, 2004; Tarducci; Tagliaferro, 2004, entre otros). Así, uno de los aspectos que ha adquirido relevancia son las múltiples modalidades en las que la iglesia católica busca influenciar en los poderes del Estado (Esquivel, 2009; Ameigeiras, 2012) tanto para evitar como para impedir y revertir la sanción de DDSSRR (Vaggione, 2011). La iglesia católica, además de participar como actor influyente cuando se debate sobre sexualidad, también opera desde la difusión de su cosmovisión. En esta dirección, las cosmovisiones religiosas puestas en circulación pública - por ejemplo, a través de pronunciamientos vaticanos o a nivel de las conferencias episcopales nacionales y regionales (Gutierrez, 2010; Guzmán; Sgró Ruata, 2009) - también juegan un rol central en la política sexual conservadora. Asimismo, algunos estudios están poniendo de relieve la presencia cada vez más visible de otros actores religiosos que se articulan en defensa de un orden sexual restrictivo, en la que se destacan sectores de las iglesias evangélicas (Natividade; Oliveira, 2009; Jones; Cunial, 2011) y organizaciones civiles autodenominadas provida-profamilia alineadas a la posición de los sectores eclesiales (Gonzáles Ruiz.; 2005; Irrazabal, 2010; Morán Faúndes, 2012).

En este sentido, las instituciones eclesiales y las organizaciones civiles con adscripción religiosa pueden entenderse como un activismo religioso conservador (Vaggione, 2010) que despliega una diversidad de estrategias para incidir en el espacio de lo público frente a procesos de politización de la sexualidad. Pero, al mismo tiempo, la religión - sus cosmovisiones - también puede entenderse como dadora de sentidos válidos respecto a lo que el mundo es o debe ser y, así, el poder de la religión radica en parte en su capacidad para participar en la construcción de conocimiento 
socialmente objetivado, necesario para justificar, explicar y mantener el orden social (Collignon, 2011,).

En este marco, nos proponemos indagar los sentidos conectados con lo religioso/la religión que atraviesan el discurso de oposición en el debate parlamentario por la ley de matrimonio igualitario en Argentina (2010). Para ello, analizamos los discursos pronunciados por los legisladores en la Cámara de Diputados (4 de mayo de 2010) y en la Cámara de Senadores (14 de julio de 2010). El interés central de este enfoque radica en tomar el debate como una instancia de observación de significaciones que alientan posiciones y que traen a escena pública lo religioso en el espacio de lo público fuerte (Fraser, 1997), en tanto lugar donde se deciden y se disputa el establecimiento de los marcos regulatorios que establecerán (al menos por un tiempo) los límites de lo admisible y que culmina, por tanto, en decisiones legalmente obligatorias.

Dicho lo anterior, en primer lugar presentamos un panorama general haciendo hincapié en el espacio de lo público y algunas características que signaron el contexto socio político de debate del proyecto de ley. A partir de esta puerta de entrada y en segundo lugar, presentamos una categorización que nos permite captar el ingreso de lo religioso en el campo de oposición parlamentaria.

\section{Puerta de entrada al debate parlamentario}

Algunos trabajos han analizado detalladamente, desde diferentes enfoques, la ley 26618 de reforma del código civil en Argentina (Clerico; Aldao, 2010; Solari; Von Opiela, 2011). En esta presentación, no hacemos foco en el proceso de la ley ${ }^{1}$, pero vale mencionar que entre las condiciones (Biglieri, 2013) que fueron cimentado el escenario para

\footnotetext{
${ }^{1}$ Para un análisis sobre el proceso que culmina en la sanción de la ley de matrimonio igualitario se puede consultar Hiller (2010).
} 
que el matrimonio igualitario logre "estado parlamentario" en el 2010 se encuentran las estrategias de los movimientos por la diversidad sexual. ${ }^{2}$ Entre ellas, se destacan lo que algunos denominan uso estratégico del derecho o litigios estratégicos (Manzo, 2011; Campana, 2011) que en Argentina se dieron a través de la presentación de amparos ${ }^{3}$ en el poder judicial por parte de parejas a quienes los registros civiles les negaban el otorgamiento de turnos para contraer matrimonio civil (Figari; Pecheny, 2010). Siguiendo a Delamata (2013), el proceso político que converge en la aprobación de la ley 26618 estuvo signado por la efectividad de las estrategias desarrolladas por el movimiento por la diversidad sexual donde se combinan la judicialización de derechos y la incidencia parlamentaria. Así y en el marco de los procesos contemporáneos ${ }^{4}$ de movilización socio legal (Delamata, 2013), paralelamente a la estrategia judicial se fueron presentando en el poder legislativo diversos proyectos de modificación del código civil los que fueron perdiendo estado parlamentario.

Interesa aquí puntualizar algunas características que de manera sucinta permiten enmarcar el debate en el ámbito parlamentario en el 2010 (año en que la ley finalmente se sanciona) y que sirven como puerta de ingreso al abordaje del discurso de oposición en las cámaras legislativas.

\footnotetext{
${ }^{2}$ Se vuelve necesario recordar que las acciones de los movimientos feministas y por la diversidad sexual en primer lugar, no pueden reducirse a determinadas estrategias ni en un mismo contexto ni a lo largo de las décadas en las que los movimientos realizan su acción política. Esto supone una heterogeneidad que es necesario subrayar. En segundo lugar y en un corte histórico, las estrategias no están ni estuvieron limitadas a la transformación de los marcos legales. Algunos autores utilizan diferentes nominaciones para analizar las variaciones tanto de las estrategias y los temas (o issues) privilegiados como las demandas de los movimientos por la diversidad en Argentina. En este sentido, por ejemplo, Pecheny (2001) considera el desplazamiento de las demandas por la no-discriminación a las estrategias de reconocimiento y Kantor (2011) el paso de un paradigma de la tolerancia a un paradigma de ciudadanía plena. ${ }^{3}$ Siguiendo a Campana (2011, p. 106), Una acción o recurso de amparo es un remedio judicial rápido que permite la intervención de un juez, con la finalidad de hacer cesar cualquier acción u omisión que amenace, lesione o viole los derechos constitucionalmente protegidos.

${ }^{4}$ En otros países de América latina se producen procesos similares, por ejemplo, en Brasil. Consultar, Mello (2012)
} 
En el mes de marzo, las Comisiones legislativas de Cámara de Diputados de la Nación - Comisión de Legislación General y de Familia, Niñez y Adolescencia - deciden realizar reuniones conjuntas ${ }^{5}$ para la discusión de los proyectos "Modificación del Código civil - institución del matrimonio para personas del mismo sexo", presentado por la Diputada Vilma Ibarra (y otros) (Expediente 0574- D-2010) y "en relación a los derechos de las relaciones de familia con inclusión de parejas del mismo sexo", presentado por la Diputada Silvia Augsburger (y otros) (Expediente 1737D-2009). ${ }^{6}$

El 15 de abril de 2010, se realiza la reunión donde las comisiones legislativas emiten dictamen (mayoría) ${ }^{7}$ que aconseja la aprobación del proyecto y sintetiza las propuestas discutidas:

... Los integrantes de las familias cuyo origen sea un matrimonio constituido por dos personas del mismo sexo, así como un matrimonio constituido por dos personas de distinto sexo tendrán los mismos derechos y obligaciones. Ninguna norma del ordenamiento jurídico argentino podrá ser interpretada ni aplicada en el sentido de limitar, restringir, excluir o suprimir el ejercicio o goce de los mismos derechos y obligaciones, tanto al matrimonio constituido por personas del mismo sexo como al formado por dos personas de distinto sexo (HCDN, Dictamen de Comisiones sobre expedientes 1737D09-0574D10, 2010, 15 de abril).

\footnotetext{
${ }^{5} \mathrm{~A}$ finales del 2009 (periodo parlamentario Num. 127) se realizaron reuniones el 29 de octubre y el 5 de noviembre y en el 2010 (periodo parlamentario Num. 128) el 18 de mayo y el 15 de abril (en esta última, se realizó la votación y emisión del dictamen).

${ }^{6}$ Estos proyectos tienen su base en algunos presentados en periodos parlamentarios anteriores. Ver, Bimbi (2010).

${ }^{7}$ Con tres disidencias totales y cinco parciales. Además, se firman dictámenes de minoría: dos bajo la propuesta de regular instituciones alternativas, como la elaboración de un régimen de "enlace civil" (firmado por los diputados Claudia M. Rucci, Eduardo P. Amadeo, Gladys González y Federico Pinedo) o un régimen de "unión familiar" (firmado la diputada Alicia Terada) y uno que aconseja el rechazo del proyecto (firmado por el diputado Mario Merlo). Ver, HCDN, Periodo de sesiones ordinarias, Orden del día Num. 197, 20 de abril de 2010.
} 
De esta manera, la emisión del dictamen habilita el ingreso del proyecto de ley a recinto de la Cámara de Diputados, donde el 4 de mayo es debatido y obtiene media sanción.

El 6 de mayo el proyecto ingresa a la Comisión de Legislación General del Senado de la Nación (CLGSN) (Expediente Num. 13/10). Luego de un periodo de reuniones, el 6 de julio, la CLGSN vota un dictamen de mayoría que aconseja el rechazo del proyecto (con media sanción en Diputados) ${ }^{8}$ junto a un con una serie de dictamines en minoría: uno refiere a la aprobación del texto devenido de Diputados y otro agrupa proyectos alternativos que aconsejan el tratamiento de una ley que regule institutos de Unión civil. ${ }^{9}$ Con este panorama, un día antes de la sesión en el Senado se presenta una impugnación ${ }^{10}$ al tratamiento de la Unión civil cuyo fundamento se basó en las atribuciones que la Constitución Nacional le otorga a las cámaras legislativas. Finalmente, la sesión en el Senado se realiza el 14 de julio y, luego de un extenso debate, el proyecto se convierte en ley (publicada en el Boletín Oficial Num. 31.949 del 22 de julio de 2010).

Una de las singularidades que adquiere el itinerario que terminamos de trazar se produce en la etapa en la que el proyecto de ley ingresa a la Comisión de Legislación General del Senado (CLGS), en especial con la decisión del traslado de sus reuniones a diferentes provincias argentinas, las que se conocieron como "audiencias públicas". ${ }^{11}$

\footnotetext{
${ }^{8}$ Orden del Día 600/2010 (A)

${ }^{9}$ Orden del Día 601/2010 (N).

${ }^{10}$ Cfr. Página 12, 08/07/2010; Perfil, 15/07/2010; Clarín, 15/07/2010; La Nación, 15/07/2010

${ }^{11}$ En la primera reunión realizada por la Comisión del Legislación General del Senado en las provincias (en la legislatura provincial del Chaco, el 10 de junio de 2010), la secretaria de la Comisión - Lidia Galiano - advierte que el evento no es una audiencia pública, sino traslados de las reuniones de comisión (citando el Art. 98 del reglamento del Senado). Sin embargo, durante el periodo, en distintos espacios de lo público (medios de comunicación, movilizaciones callejeras, etc.), se adoptó la denominación "audiencias públicas" por lo que optamos por continuar utilizando este término.
} 
El 19 de mayo de 2010 la senadora Liliana Negre de Alonso, presidenta de CLGS, presenta un proyecto de resolución en el que se solicita constituir la Comisión en diferentes ciudades del país con el objetivo de permitir la participación de distintos actores sociales en el debate del proyecto de ley que modifica diversos artículos del Código civil respecto a incluir el matrimonio de parejas conformadas por Personas del mismo sexo (HSN, Expte. 1390/10, 19 de mayo de 2010). Así, durante los meses de junio y julio, se realizaron audiencias públicas en las provincias de Córdoba, Catamarca, Jujuy, Salta, Tucumán, San Juan, Chaco, Corrientes y Mendoza, además de las planificadas desde un comienzo en Capital Federal.

En esta dirección, resulta relevante señalar dos cuestiones relacionadas con lo anterior: en primer lugar, en algunas audiencias públicas, estuvieron presentes legisladores nacionales representantes de las provincias, lo cual creó condiciones de posibilidad para la interpelación directa a los legisladores por parte de los participantes (Sgró Ruata, 2011a). En segundo lugar, en torno a las audiencias públicas, en algunas provincias, se organizaron marchas callejeras en "defensa del matrimonio y la familia", en las que se movilizaron diferentes sectores para manifestar su oposición al proyecto de ley. Así, el contexto de debate parlamentario estuvo acompañado de una serie de prácticas que buscaron intervenir en los espacios públicos, interpelar al poder legislativo e influir en el futuro de la ley.

De hecho, en reiteradas ocasiones los participantes de las audiencias públicas, las marchas callejeras e incluso las declaraciones puestas en circulación pública por las jerarquías religiosas, reservaron un apartado para explicitar la demanda directa a los legisladores y exigir el voto en rechazo al proyecto de ley en discusión. Por ejemplo, en Córdoba una de las primeras provincias en las que se realizaron marchas callejeras, los oradores del acto final se dirigieron directamente a los representantes provinciales poniendo en explícito la demanda: 
A los señores senadores nacionales por Córdoba, Luiz Juez, Norma Morandini y Ramón Mestre: los ciudadanos y ciudadanas e instituciones aquí reunidos en la Capital de la provincia que los eligió senadores nacionales, nos dirigimos a ustedes para solicitarles defiendan en el Congreso de la Nación, la institución del matrimonio conformado única y exclusivamente por varón y mujer. (...) señores Senadores por Córdoba, al votar esta ley cae sobre ustedes el peso de decidir el futuro de la familia argentina. Sepan hacerlo con responsabilidad. (Registro de campo, documento leído al finalizar la marcha el 18 de mayo de 2010). ${ }^{12}$

La jerarquía de la iglesia católica también buscó interpelar a los legisladores mediante declaraciones públicas de la Conferencia Episcopal Argentina (CEA) o de sus Obispos los que incluso participaron como asistentes, organizadores y promotores de las marchas callejeras en algunas localidades del país (Sgró Ruata, 2011b). De los cuantiosos ejemplos que pueden registrarse durante el transcurso del debate parlamentario, uno de los que tuvo mayor repercusión en los medios de comunicación fue la publicación de una carta firmada por el Cardenal Bergoglio (entonces, presidente de la CEA y actual Sumo Pontífice) que ingresa al discurso mediático cercano a la fecha de votación final del proyecto en el Senado nacional (julio de 2010). En este documento, además de definir la situación en términos de "guerra de Dios" invoca al señor para que envíe su espíritu a los senadores (p.229) exponiendo de esta manera su posición y apostando a incidir en los legisladores para que rechacen el proyecto de ley.

Asimismo, la iglesia católica y algunas iglesias evangélicas a nivel institucional reafirmaron su posicionamiento público con declaraciones que exponen argumentos de rechazo al matrimonio igualitario y convocan a los legisladores a votar en consecuencia. La CEA, por ejemplo en el documento final de la 99 Asamblea plenaria (abril 2010) expresó: Apelamos a

\footnotetext{
${ }^{12} \mathrm{Si}$ no se indica lo contrario, de aquí en adelante los resaltados son nuestros.
} 
la conciencia de nuestros legisladores para que, al decidir sobre una cuestión de tanta gravedad, tengan en cuenta estas verdades fundamentales, para el bien de la Patria y de sus futuras generaciones. ${ }^{13}$ En la misma dirección, la Alianza Cristiana de Iglesias Evangélicas de Argentina (ACIERA), la Federación Confraternidad Evangélica Pentecostal (FECEP) pusieron en circulación pública un documento que luego de brindar argumentos de rechazo al proyecto invoca a Dios como fuente de toda razón y justicia, a fin de que Él ilumine las mentes de los ciudadanos y especialmente de los Senadores de la Nación frente a un tema de tanta importancia para todos argentinos. ${ }^{14}$ Los ejemplos anteriores, sirven para poner de relieve que, en el contexto de debate parlamentario, en diferentes espacios de lo público (audiencias públicas, marchas callejeras, entre otros) la demanda a los legisladores ocupó un lugar significativo en las prácticas de oposición al matrimonio igualitario.

\section{Lo religioso en el campo de oposición parlamentaria}

En el debate parlamentario, 79 legisladores intervinieron como oradores en la Cámara de Diputados (lo que representa un 31\% del total de miembros) y 52 en la Cámara de Senadores (72\%). Entre las intervenciones en cada una de las sesiones de votación, 26 exposiciones en la Cámara de Diputados y 22 en la de Senadores conforman lo que denominamos campo de oposición parlamentaria. ${ }^{15}$

\footnotetext{
${ }^{13}$ Se puede consultar en AICA: www.aicaold.com.ar/docs_blanco.php?id=226;

${ }^{14}$ Se puede consultar en www.aciera.org

${ }^{15}$ Para la construcción del campo de oposición parlamentaria, en primer lugar, seleccionamos como material de observación las transcripciones de las sesiones de votación: a) Sesión legislativa del 4 de mayo de 2010 en la Cámara de Diputados de la Nación (Séptima Reunión, Cuarta Sesión Ordinaria -Especial, 4 de mayo de 2010) y b) Sesión legislativa del 15 de julio en Cámara de Senadores nacionales (Décimo cuarta Reunión, Novena Sesión ordinaria, 14 y 15 de julio de 2010). En segundo lugar, realizamos una sistematización del material discursivo mediante la asignación de lo que denominamos "marcas de posición" (operacionalizando la noción de marcas propuesta por Verón, 1993) cuyo objetivo consiste en detectar los posiciona-
} 
En este campo, adquieren relevancia un conjunto de remisiones significativas que convoca a la religión/lo religioso como dimensión operante del debate conformada por la presencia de referencias a adscripciones religiosas o identidades conectadas con la religión. Así, aunque buscan más bien subordinarse o desplazarse ${ }^{16}$ de las intervenciones, sentidos vinculados de manera explícita con lo religioso ingresan al debate parlamentario, en especial, mediante la adscripción religiosa de los legisladores (que como veremos, se refiere casi exclusivamente a la religión católica).

Para captar las maneras en las que lo religioso ingresa al campo de oposición parlamentaria, distinguimos tres categorías analíticas: 1) Explicitación de la propia identidad religiosa por parte del legislador que denominamos «(auto) identificación» 2) Identificación adjudicada a un Otro que en el marco de este trabajo denominamos «alter-creyente». ${ }^{17} \mathrm{Ambas}$,

mientos específicamente a partir de la lectura de lo expresado en las intervenciones (es decir, independientemente del voto final emitido por los legisladores al finalizar la sesión) y clasificarlos utilizando el criterio: posicionamiento respecto al matrimonio entre personas del mismo sexo (así, el foco de la clasificación de las "marcas de posición" es la modificación del código civil en relación a la institución matrimonio y no los dictámenes emitidos por las comisiones legislativas). Este procedimiento se realizó sobre la totalidad de las intervenciones legislativas registradas: 79 en Diputados y 52 en Senadores. Realizamos este trabajo con la asistencia del software Atlas.ti, herramienta que nos facilita el manejo de material textual de amplias magnitudes. Así, el corpus de análisis definitivo quedó constituido por 26 exposiciones en Cámara de Diputados y 22 exposiciones en el Senado de la Nación las que conforman para este trabajo, el campo de oposición parlamentaria.

${ }^{16}$ Esto excede los objetivos de este trabajo, pero se vuelve necesario mencionarlo dado que, en nuestro análisis, una lectura cruzada permite reconocer ciertas conexiones con otros discursos en oposición puestos en circulación pública del orden de lo religioso o lo sagrado que pueden no estar referidos en las intervenciones parlamentarias (al menos de manera directa o explícita) pero que encuentran en ellas vinculaciones.

${ }^{17}$ Construimos esta categoría como forma de captar una de las conexiones de lo religioso/lo político. Utilizamos el término Alter en lugar de Otro para subrayar que: alter en este contexto implica la referencia a un Otro que no se construye como diferente sino como un otro-social, representativo de quien lo convoca. Así, la categoría de «alter-creyente» supone que el "ser creyente" se desplaza de una dimensión personal a una social (se trata de condición de la sociedad como un todo). El Otro se generaliza así, en términos de cultura nacional; pero desde el momento en que se asumen para si los principios que la articulan (esto es, se asume como parte de la cultura que define) ese Otro (creyente) es asumido por el que habla. De esto se de- 
pueden relacionarse a manera de apoyatura o excluirse, pero lo que resaltamos es que mientras la primera implica una afiliación a creencias religiosas desde la propia identificación, la segunda lo hace desde la identificación colectiva. Así, mientras la primera supone un sujeto que se reconoce públicamente como creyente y desde allí esgrime argumentos cuyas remisiones son e implican sentidos vinculados con la fe (interpretaciones afines a los textos doctrinarios), la segunda se desplaza a un sujeto colectivo. Por esta razón, decimos que la primera es del orden específicamente de la identificación mientras que la segunda pertenece al de la estrategia (como veremos en los apartados que siguen). Por último, si bien la religión/lo religioso ingresa a través de formas de identificación (propia y social), también encontramos un ingreso a partir de un desplazamiento-alejamiento que conforma lo que en este trabajo definimos como 3) «des-identificaciones» (ver gráfico 1).

riva más un acercamiento-identificación que un alejamiento, aun cuando estratégicamente se esté buscando lo segundo. Por esta razón decidimos utilizar el término "alter" para marcar una "subjetividad semejante a la mía" más que una diferenciación producto del reconocimiento del Otro como subjetividad diferente. Asimismo, utilizamos el término creyente en lugar de religioso para marcar que la conexión no está dada por una religión en especial, sino por la subjetividad de creer, es decir, se produce en torno a las creencias religiosas colocadas como componente de identidad. 


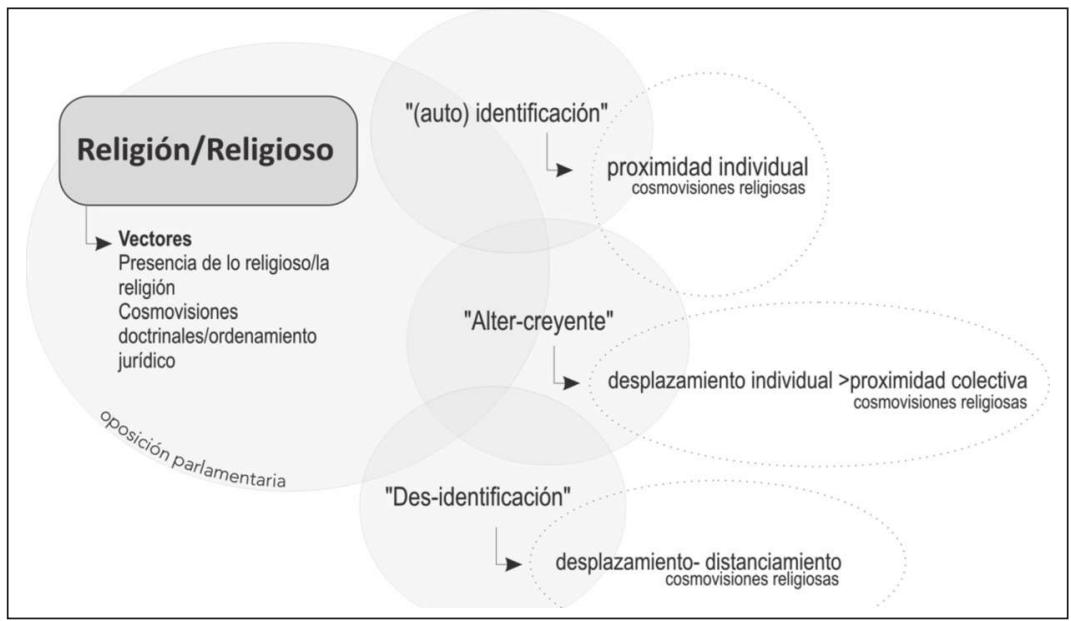

Gráfico 1. Presencia de lo religioso en los discursos de oposición parlamentaria

\section{II.1. (Auto)identificación}

Auto-identificación supone, en este marco de trabajo, que los legisladores decidieron poner en escena pública su identidad religiosa explicitando la pertenencia a una religión o prestando su acuerdo/sentir con cosmovisiones religiosas.

Porque respeto a la ciudadanía y a mis semejantes con una profunda convicción: no venimos aquí a esconder la fe que tenemos cada uno de nosotros. Profeso la fe del cristianismo, soy católico, y creo que lejos de mí está discriminar a nadie. Cejas, J., diputado

(...) Soy católico, pero no las comparto; y en esto coincidimos, señor senador. Cimadevilla, M., senador.

En el caso de este senador de la Nación, con una fuerte formación católica y con un fuerte compromiso con este 
gobierno, me resulta muy difícil estar sentado en esta banca y votar a favor o en contra de este proyecto (....) Jenefes, G., senador.

(...) antes de dar razón de mi voto negativo al proyecto aprobado por la Cámara de Diputados, quiero expresar que no abjuro, reniego ni oculto la fe que profeso ni mi pertenencia a la Iglesia católica, porque tengo la certeza de que no es motivo para descalificar la postura que asumo. Monllau, B., senadora.

(...) Entonces, los que creemos que Dios existe, lógicamente, también pensamos que rige nuestras vidas. Mayans, J., senador.

Y, por supuesto, repudio todas las actitudes delictivas, vengan del sector que vengan, cualquiera sea el sujeto que las haya cometido, aunque las haya cometido la gente de la religión a la que pertenezco. No he traído el tema religioso acá. Negre de Alonso, L., senadora ${ }^{18}$.

En la oposición parlamentaria, la doctrina católica adquiere preeminencia al momento de explicitar públicamente la adscripción religiosa ${ }^{19}$ pero más allá de esto, resulta interesante subrayar que ingresa como una manera de poner en tensión la aprobación de la ley con la pertenencia al catolicismo; en otras palabras, como demarcación de la contraposición que supone la ampliación de derechos sexuales y reproductivos con la (propia) identidad religiosa, cuestión que convoca, de alguna manera,

\footnotetext{
${ }^{18}$ Más allá de las puestas en escena pública en el parlamento, es interesante mencionar que, en relación a las disputas en torno al proyecto de ley en otros lugares de lo público, como, por ejemplo, en las marchas callejeras en defensa de la familia o en los medios de comunicación, dos legisladoras - la diputada nacional C. Hotton y la senadora nacional L. Negre de Alonso adoptaron un rol protagónico en el activismo en contra del matrimonio igualitario. Ambas se vincularon públicamente como pertenecientes a las religiones evangélica y católica respectivamente. Sin embargo, en las sesiones de votación, no expresaron - al menos directamente - su pertenencia religiosa, más bien al contrario.

${ }^{19}$ Vale mencionar que se observaron algunas excepciones también a nivel explícito, como, por ejemplo, una diputada se identificó con el budismo.
} 
los lineamientos doctrinales que la jerarquía católica (desde el Vaticano hasta la Conferencia Episcopal Argentina) viene promoviendo en relación a estos temas. ${ }^{20}$

En esta dirección, en algunas ocasiones, el discurso oficial de la iglesia católica ingresa literalmente pasando a formar parte de la intervención legislativa. Los sentidos puestos en circulación pública de esta manera van conformando un entramado que posibilita fusionar el deber ser sustentado en discursos doctrinales; la referencia directa a documentos pontificios por ejemplo, habilita e inscribe al mismo tiempo, a la doctrina católica como fuente legítima para fundamentar la posición en el debate parlamentario.

Y cuando decimos "libre albedrío" nos estamos refiriendo a un párrafo bíblico, algo que Dios nos legara, en cuanto a la posibilidad de elegir entre el camino correcto y el camino incorrecto. En esta oportunidad voy a expresar la posición de nuestro bloque fundándola en la fe. En este sentido, me voy a referir a los capítulos I y II del Génesis, donde podemos leer: "Y Dios creó al hombre a su imagen; lo creó a imagen de Dios, los creó varón y mujer." "Luego, con la costilla que había sacado del hombre el Señor Dios formó una mujer y se la presentó al hombre. El hombre exclamó: 'iEsta sí que es hueso de mis huesos y carne de mi carne! Se llamará mujer". "Y los bendijo, diciéndoles: Sean fecundos, multiplíquense, Ilenen la tierra y sométanla". Ledesma, J., diputado.

\footnotetext{
${ }^{20}$ La Conferencia Episcopal Argentina, como en otras ocasiones cuando se debaten políticas sobre sexualidad y reproducción, realizó diferentes declaraciones para afirmar su posición pública en el contexto del matrimonio igualitario. Por su parte el Vaticano, ha publicado documentos que abordan específicamente las uniones entre personas del mismo sexo e incluso instruyen a los legisladores católicos sobre el modo de actuar cuando ingresan en agenda legislativa estos temas (por ejemplo, Consideraciones acerca de los proyectos de reconocimiento legal de las uniones entre personas homosexuales, Congregación para la Doctrina de la Fe, 2003). No es posible abordar esta dimensión en esta presentación, pero numerosos trabajos ponen de relieve el discurso de las jerarquías religiosas cuando se debaten políticas sexuales. Se puede consultar: Vaggione (2010); Esquivel (2013).
} 
El Papa Juan Pablo II en su Exhortación Apostólica "Familiaris Consortio" de noviembre del año 1981, escrita a la luz de lo que la Iglesia avizoraba como un avance sobre la institución de la familia cristiana, indicaba que: "La sexualidad, mediante la cual el hombre y la mujer se dan uno a otro con los actos propios y exclusivos de los esposos, no es algo puramente biológico sino que afecta el núcleo íntimo de la persona humana en cuanto tal (...) Y agrega: "La institución matrimonial no es una injerencia indebida de la sociedad o de la autoridad ni la imposición intrínseca de una forma, sino exigencia interior del pacto de amor conyugal que se confirma públicamente como único y exclusivo, para que sea vivida así la plena fidelidad al designio de Dios Creador." Robledo, R., diputado.

Apelo a algo que decía San Agustín, un gran santo de la cristiandad, respecto de que uno no debe creerse más de lo que es. Todos los días un sacerdote le decía: "Agustín, eres simplemente un hombre" (...) Si hay alguien que nos va a igualar a todos los que estamos aquí presentes con una $u$ otra postura y los que están en los palcos, con una u otra postura, es el infinito amor de Dios. Cejas, J., diputado.

La penetración de discursos del orden religioso también se produce en torno a lo programático, esto es, en sujeción a las formas de actuar propuestas por las jerarquías eclesiales frente a situaciones concretas. Así, la (auto) identificación también implica la construcción de la iglesia católica como autoridad y su discurso oficial como mandato para quienes como católicos participan del decir y hacer legislativos.

Para concluir, voy a citar a Su Santidad el Papa Benedicto XVI, cuando era prefecto de la Congregación para la Doctrina de la Fe. El Sumo Pontífice dijo que en el caso de que en una asamblea legislativa se proponga por primera vez un proyecto de ley a favor de la legalización de las uniones homosexuales, el parlamentario católico tiene el deber moral de expresar clara y públicamente su desacuerdo y votar en contra del proyecto de ley. Conceder 
el sufragio o el propio voto a un texto legislativo tan nocivo del bien común de la sociedad y de la familia es un acto gravemente inmoral. Ledesma, J., diputado.

En este entramado, las fronteras entre lo estatal y lo religioso se relativizan y al colocarse la religión como ordenadora de la cultura (occidental) se coloca al mismo tiempo como parte de la propia gestación del Estado y del orden jurídico argentino. Esto permite generar ciertos modos de aproximación entre las cosmovisiones religiosas y el establecimiento de los órdenes legales al proponer que ambas esferas se encuentran conectadas en valores y creencias compartidas socialmente. Así, el desplazamiento hacia el eje religión-cultura fortalece la mirada legitimadora del orden de lo religioso en la conformación del orden jurídico.

Pero en realidad, en la historia judeocristiana, esto está sumamente vinculado. Si nosotros nos queremos olvidar absolutamente de la religión o mirar desde el positivismo las limitaciones y las regulaciones, veremos que en casi todos los códigos penales del mundo están penados el hurto, el homicidio, la violación, los abusos sexuales (...) De hecho, si vamos al origen de la religión judeocristiana, los Diez Mandamientos no hacen ni más ni menos que penar: no robarás, no cometerás adulterio, no violarás, etcétera. O sea que por más que queramos separarlos Ilega un momento en que por nuestra misma historia y nuestra misma tradición tienen un argumento en común. Negre de Alonso, L., senadora.

Es decir, convengamos que muchos de los conceptos de las religiones, hoy, están volcados al Derecho positivo. Una de las preguntas que nos hacemos -al menos, yo- es si en función de la diversidad de sexo, se puede legislar o no. Cimadevilla, M., senador.

Por ahí, también se dijo que no hay que mezclar las cuestiones de Dios con las del Estado. Pero fíjense que este Estado nació al amparo de Dios, que es fuente de toda 
razón y justicia. Entonces, los que creemos que Dios existe, lógicamente, también pensamos que rige nuestras vidas. Por eso es que, cuando actuamos, lo debemos hacer en función de ello. Mayans, J., senador.

Por último, la (auto)identificación religiosa sirve para fundamentar la oposición en base a los preceptos establecidos por las instituciones religiosas pero también sienta sus bases en los principios sostenidos formalmente por el Estado. De hecho y en esta dirección, la propia identidad católica es fortalecida y defendida con la explicitación del artículo número 2 de la Constitución Nacional ${ }^{21}$ y se vuelve marco interpretativo operante para sostener la posición frente al debate.

El artículo $2^{\circ}$ de nuestra Constitución Nacional dice: "El Gobierno federal sostiene el culto católico apostólico romano." Es por eso que vengo a defender mi posición desde la fe, pero también desde el derecho. Ledesma, J., diputado.

Al respecto, así como la Constitución Nacional en el artículo $1^{\circ}$ establece ciertos preceptos superiores sobre los que debe asentarse la conformación, organización y funcionamiento del Estado argentino, el artículo que lo sucede, independientemente de la variedad de interpretaciones que se puedan efectuar sobre su alcance, define claramente principios y concepciones que orientan el orden social que hay que tener y la arquitectura del sistema jurídico sobre el que se sustenta (...) La Ley Fundamental, la que fija los límites y define las relaciones entre los poderes Legislativo, Ejecutivo y Judicial del Estado, la que establece las bases para su gobierno y ordenación de las instituciones en que tales poderes se asientan y que también garantiza al pueblo aquellos derechos y libertades más esenciales, tiene como uno de sus principios rectores el sostenimiento del culto católico, y junto a él, de los institutos que el credo protege. Fernández, R., diputado.

\footnotetext{
${ }^{21}$ Un panorama de las relaciones Iglesia católica y Estado argentino, en especial, sobre los marcos normativos vigentes se puede consultar Esquivel (2010).
} 


\section{II.2. Alter creyente}

Otras de las formas en las que los sentidos desplegados en la oposición parlamentaria están en conexión con identificaciones religiosas para justificar el rechazo a la ley es la adjudicación de esa identificación a un Otro (colectivo de creyentes). Consideramos que esta forma es estratégica puesto que si, por un lado, busca desvincularse del compromiso particular con una cosmovisión religiosa, por otro, deposita las creencias religiosas en la identidad de un otro, cuestión que habilita - de igual manera - el ingreso de lo religioso al debate y la defensa de la posición.

El desplazamiento estratégico consiste en subrayar la importancia de la fe (cosmovisiones religiosas) en la discusión parlamentaria desde una posición no-religiosa. Pero, esta posición no-religiosa pone en escena sentidos conectados con cosmovisiones religiosas y les otorga materialidad, a partir de la identificación con ese otro creyente (que es construido como el depositario y en nombre del cual se fundamenta la posición). Lo denominamos «alter-creyente», justamente porque consideramos que se construye como identidad diferente - sólo - en términos estratégicos, es decir, como manera de evadir justificaciones con base religiosa, pero asumiéndolas como parte constitutiva de la propia posición, a través de materializar en la propia voz, la voz de un colectivo generalizado de creyentes.

Es una realidad que en torno a esta cuestión existen diversas barreras -culturales, ideológicas y religiosas - que aún no han madurado en el seno de la sociedad. Por lo tanto, esta es una instancia que como legisladores no podemos obviar. Por estas razones, estimo que es fundamental continuar con el diálogo y con la discusión tolerante sobre cuestiones tan caras a nuestra idiosincrasia. Fortuna, F., diputado.

Yo creo que, poco a poco, la sociedad fue admitiendo esta diversidad existente con relación a los homosexuales, y res- 
Sociologias, Porto Alegre, ano 19, no 44, jan/abr 2017, p. 248-274

petando esa diversidad. También creo que tenemos que respetar la diversidad de aquellos que han adoptado el matrimonio heterosexual por razones culturales, por razones naturales, por creencias, incluso por razones religiosas. Me parece que también ese es un derecho que tiene que ser respetado. Lores, H., senador.

Así, la figura del alter-creyente es una forma estratégica de poner en escena sentidos des-adheridos de cosmovisiones religiosas, pero poniéndolas de relieve desde el reconocimiento. Y del mismo modo que la «auto-identificación», fortalece la mirada legitimadora del orden de lo religioso en la conformación del orden jurídico.

\section{II.3. Des-identificaciones}

Un debate que coloca como centro el otorgamiento de un derecho, habilitando al mismo tiempo fundamentos del orden sagrado religioso, provoca la necesidad de definir los espacios de lo religioso y lo político (asociados con la iglesia y el Estado respectivamente). Esta necesidad de demarcar espacios se vuelve interesante en relación al núcleo de sentidos relacionados con la religión, porque es justamente una de las maneras en las que lo religioso se visibiliza como parte (aún en términos de separación) del debate. Esto es, en tanto y en cuanto la religión es convocada en el debate, da cuenta de la influencia que el discurso religioso sigue teniendo en discusiones sobre sexualidad. Matrimonio y familia son dos significantes centrales en el discurso del catolicismo y la posición sostenida en el espacio público por parte de la iglesia - al menos desde su jerarquía - implica una práctica sostenida en la defensa de un orden basado en el amor conyugal como base de la familia (heterosexual).

La delimitación de fronteras supone la necesidad de des-identificar los sentidos puestos en circulación de una cosmovisión religiosa tratando 
de definir asimismo lo público y lo privado, situando las creencias religiosas como parte de este último.

A diferencia del alter-creyente (que busca el alejamiento, pero a la vez ejerce el reconocimiento) des-identificación implica el intento de aislar las creencias religiosas del debate parlamentario desplazándolas al terreno de lo privado; pero, en ese mismo movimiento, se reconoce la conexión entre los sentidos que fundamentan la posición y los defendidos por la religión y, justamente por eso, la necesidad de explicitar la separación. En otras palabras, a través de la des-identificación se busca despegar lo religioso del debate parlamentario trazando límites entre lo público/ privado (colocando la religión del lado de lo privado).

La concepción hombre-mujer no la podemos negar, está desde el principio de los siglos y la unión de hombre-hombre o mujer-mujer es algo que debe estudiarse en el sentido de si se le va a dar una palabra o una institución jurídica. Acá no estoy hablando desde el punto de vista religioso porque creo que en ese aspecto cada uno tiene sus concepciones y desde ese punto lo defendemos. Perez Alsina, J., senador.

La República reconoce las diferencias y las contiene, y en ese sentido creo que es muy necesario que separemos nuestras convicciones religiosas, porque en todo caso debemos tratar de practicar esos valores todos los días. Muchas veces por nuestras propias vulnerabilidades y debilidades no nos sale tan bien -en última instancia ese es el testimonio que tenemos que dar de nuestros valores-, pero a la hora de generar normas y reglas de juego de la República-insisto- creo que hay que separar muy bien las convicciones religiosas de las republicanas. Michetti, G., diputada.

Así, situando lo religioso en lo privado y el debate parlamentario en lo público se busca inscribir el rechazo a la ley desvinculando de manera explícita cualquier dimensión de índole religiosa. De lo anterior, decimos 
que la religión/lo religioso filtra el debate tomando cuerpo en las intervenciones legislativas como factor de influencia política.

\section{Líneas de cierre}

Frente a la puesta en discusión del requisito de complementariedad de los sexos para la conformación del matrimonio reconocido por el Estado y, en consecuencia, la posibilidad de adopción (conjunta) por parte de parejas del mismo sexo (minando la heteronormatividad inscripta en lo legal) emergen sentidos que, en atadura con el discurso oficial de la iglesia católica, traen e instalan, en el debate parlamentario, cosmovisiones religiosas. En definitiva, la religión ingresa como sentido definidor, como dadora de sentido en el público fuerte (es decir, en las instancias de decisión de las leyes civiles) (Fraser, 1997).

Como corolario, se abre la pregunta sobre el lugar de la identidad religiosa en los debates en los que las instituciones religiosas - vividas como orientadoras de interpretación - dan una disputa visible en el contexto sociopolítico, sosteniendo sistemáticamente posiciones públicas respecto a la defensa del orden natural y la familia nacional y cristiana como sentidos medulares de la (única) interpretación posible para los fieles. Pero, más allá del lugar que lo religioso debe(ría) tener en el parlamento, el campo de oposición parlamentaria pone en evidencia que disputar la regulación del orden sexual trae a escena, de maneras más o menos directas, lo religioso como dimensión operante en el debate. Así, el intento de delinear límites nítidos entre lo religioso y lo político se desplaza para poner en foco justamente la necesidad de repensar la fragilidad de sus contornos.

María Candelaria Sgró Ruata es Doctora en Estudios Sociales de América Latina, Universidad Nacional de Córdoba, Argentina, $M$ candelariasgro@yahoo.com 


\section{Referencias}

1. AMEIGEIRAS, A. (coord.) Cruces, intersecciones, conflictos. Relaciones político religiosas en Latinoamérica. Buenos Aires: CLACSO, 2012.

2. ARAUJO, K. Sobre ruidos y nueces: debates chilenos en torno a la sexualidad. En: VAGGIONE, J. (Comp.). El activismo religioso conservador en Latinoamérica. Córdoba: CDD, 2010. pp.77-108

3. BIGLIERI, P. Emancipaciones. Acerca de la aprobación de la ley del matrimonio igualitario en Argentina. Íconos Revista de Ciencias Sociales, Quito, n. 46, pp. 145-160, 2013.

4. BIMBI, B. Matrimonio igualitario. Intrigas, tensiones y secretos en el camino hacia la ley. Buenos Aires: Planeta, 2010.

5. CAMPANA, M. ¿Será justicia? La cuestión del matrimonio igualitario en los tribunales cordobeses. En: SGRÓ RUATA et al. El debate sobre matrimonio igualitario en Córdoba. Actores, Estrategias y discursos. Córdoba: Ferreyra/CDD, 2011. p. $105-136$

6. CLARIN. El Senado convirtió en ley el matrimonio homosexual. Disponible en:_http://www.clarin.com/sociedad/Senado-convirtio-Ley-matrimonio homosexual_0_298770299.html_Acceso: diciembre 2011.

7. CLERICO, L.; ALDAO, M. (Coords.) Matrimonio igualitario. Perspectivas políticas y jurídicas. Buenos Aires: Eudeba, 2010.

8. COLLIGNON GORIBAR, M. Discursos sociales sobre la sexualidad: narrativas sobre la diversidad sexual y prácticas de resistencia. Comunicación y Sociedad, Guadalajara, n. 16, pp. 133 -160, 2011.

9. DELAMATA, G. Movimientos sociales, activismo constitucional y narrativa democrática en la Argentina contemporánea. Sociologias, Porto Alegre, año 15, n. 32, pp. 148-180, 2013.

10. DIDES, C. (Comp.) Diálogos Sur-Sur sobre religión, derechos y salud sexual y reproductiva: los casos de Argentina, Colombia, Chile y Perú. Chile: Progénero, 2004.

11. ESQUIVEL, J. C. ¿Religión oficial? La preponderancia católica en la legislación nacional y provincial. Agencia Latinoamericana y Caribeña de Comunicación, Quito, 2010. Disponible en: http://www.nuevatierra.org.ar/2010/10/248/ Acceso: enero 2011

12. ESQUIVEL, J. C. Narrativas religiosas y políticas en la disputa por la educación sexual en Argentina. Cultura y Religión, v. VII, n. 1, p. 140-163, enero/ junio, 2013. 
13. ESQUIVEL, J. Cultura política y poder eclesiástico. Archives de sciences sociales des religions, n. 146, abril/junio, 2009. Disponible en: http://assr.revues. org/21217 Acceso: abril 2015.

14. FASSIN, E. Género, sexualidades y política democrática. México: UNAM y Pueg/Colmex, 2009.

15. FIGARI, C.; PECHENY, M. Habemus igualdade. [online] Centro Latinoamericano en Sexualidad y Derechos Humanos. Brasil: CLAM, 2010. Disponible en: http://www.clam.org.br/busca/conteudo.asp?cod=7003.

16. FRASER, N. Iustitia Interrupta. Bogotá: Siglo del Hombre Editores, 1997.

17. GONZÁLEZ RUIZ, E. Cruces y sombras. Perfiles del conservadurismo en América latina. México: Promsex, 2005.

18. GUTIERREZ, M. A. Voces polifónicas. Sexualidades e identidad de género. Debate con el Fundamentalismo religioso. En: VAGGIONE, J. Activismo religioso conservador en Latinoamérica. Córdoba: Ferreyra-CDD, 2010. p.109-148

19. GUZMÁN, V.H.; SGRÓ RUATA, M. C. El Vaticano y las mujeres. En: PEÑAS DEFAGO, M. A.; SGRÓ RUATA, M. C. (comps.). Género y Sexualidad. Pluralismos y disidencias religiosas. Colección: Religión, Género y Sexualidad Córdoba: Ferreyra/CDD, 2009. pp. 117-141.

20. HILLER, R. Matrimonio igualitario y espacio público en Argentina. En: CLÉRICO, L.; ALDAO, M. (coords.) Matrimonio igualitario. Perspectivas políticas y jurídicas. Buenos Aires: Eudeba, 2010. pp. 85- 130.

21. HCDN - Honorable Cámara de Diputados de la Nación. Dictamen de Comisiones sobre expedientes 1737D09-0574D10, 15 de abril, 2010.

22. HCDN -Honorable Cámara de Diputados de la Nación. Versión taquigráfica: Período de sesiones ordinarias, Orden del día Núm. 197, 20 de abril, 2010.

23. IRRAZÁBAL, G. El derecho al aborto en discusión: la intervención de grupos católicos en la comisión de salud de la Legislatura de la Ciudad de Buenos Aires. Sociologias, Porto Alegre, año 12, n. 24, p. 308 - 336, 2010.

24. JONES, D.; CUNIAL, S. Evangélicos contra el «matrimonio homosexual» en Argentina: el activismo político de la federación Alianza Cristiana de Iglesias Evangélicas de la República Argentina (ACIERA). En: PEÑAS DEFAGO, M. A.; VAGGIONE, J. M. (comps.) Actores y discursos conservadores en los debates sobre sexualidad y reproducción en Argentina. Córdoba: Ferreyra- CDD/UE, 2011. pp. 199- 230

25. KANTOR, D. Minorías sexuales: sobre el paradigma de la Tolerancia y el paradigma de la Ciudadanía Plena. Política y Cultura, UNAM, n.35, pp. 111-128, 2011. 
26. LA NACION. Boda gay: crece la incertidumbre en el Senado. Disponible en: http://www.lanacion.com.ar/1284571-boda-gay-crece-la-incertidumbre-enel-senado Acceso: diciembre 2011.

27. MANZO, M. Uso estratégico del derecho: reconocimiento del matrimonio de parejas del mismo sexo en Argentina. Master Works, Oñati Socio-Legal Series, v. 1, n. 1, 2011.

28. MEJÍA, M. C. Sexualidad y derechos sexuales: el discurso de la Iglesia católica. Debate Feminista, México, v. 27, pp. 45 - 56, 2003.

29. MELLO, L. Direitos conjugais e familismo no Brasil pós-Lula: seriam lésbicas e gays a última minoria romântica? En: XXX International Congress of the Latin American Studies Association. San Francisco: Anais Eletrônicos, 2012.

30. MORÁN FAÚNDES, J. M. Sexualidad y alteridad: argumentos del conservadurismo religioso cordobés contra el matrimonio «igualitario». Sociedade e Cultura, Brasil, v. 15, n. 2, pp. 347-358, 2012.

31. NATIVIDADE, M.; OLIVEIRA, L. Sexualidades ameaçadoras: religião e homofobia(s) em discursos evangélicos conservadores. Sexualidad, Salud y Sociedad, n. 2, pp. 121-161, 2009.

32. PÁGINA 12. El oficialismo pidió la impugnación del proyecto de unión civil. Disponible en: http://www.pagina12.com.ar/diario/ultimas/20-149101-2010-07-08.html. Acceso: diciembre 2011.

33. PECHENY, M. De la "no-discriminación" al "reconocimiento social". Un análisis de la evolución de las demandas políticas de las minorías sexuales en América Latina. Actas XXIII Congreso LASA, 2001.

34. PECHENY, M.; DE LA DEHESA, R. Sexualidades y políticas en América latina. Un esbozo para la discusión. En: CORRÊA, S.; PARKER, R. (orgs.) Sexualidade e política na América Latina: histórias, interseções e paradoxos. Rio de Janeiro: ABIA, 2011. p 31-79

35. PERFIL. El Senado convirtió en ley el matrimonio gay. Disponible en: http://www.perfil.com/politica/El-Senado-convirtio-en-ley-el-matrimoniogay-20100714-0032.html_Acceso: diciembre 2011.

36. SGRÓ RUATA, M. C. Matrimonio entre personas del mismo sexo. Estrategias político discursivas de oposición en la Audiencia Pública de Córdoba. En: SGRÓ RUATA el al.. El debate sobre matrimonio igualitario en Córdoba. Actores, estrategias y discursos. Córdoba: Ferreyra Editor/CDD, 2011a. p. 179-231. 
37. SGRÓ RUATA, M. C. Prácticas Públicas Políticas. Marchas y movilizaciones conservadoras en torno al matrimonio entre personas del mismo sexo. En: PEÑAS DEFAGO, M.A.; VAGGIONE, J.M. (comps.) Actores y discursos conservadores en los debates sobre sexualidad y reproducción en Argentina. Córdoba: Ferreyra Editor-CDD/UE, 2011b. p. 163- 198.

38. SOLARI, N.; VON OPIELA, C. (coords.) Matrimonio entre personas del mismo sexo, Ley 26618: antecedentes, implicancias, efectos. Buenos Aires: La ley, 2011.

39. TARDUCCI, M.; TAGLIAFERRO, B. Iglesia católica: Argentina, ni diversa ni laica. POLCUL, n. 21, pp. 191 - 200, 2004.

40. VAGGIONE, J. M. Las familias más allá de la heteronormatividad. En: MOTTA, C.; SAEZ, M. (eds.) La Mirada de los Jueces. Vol II. Sexualidades diversas en la jurisprudencia latinoamericana. Bogotá: Siglo del Hombre editores, 2008. p. 13-87

41. VAGGIONE, J. M. (comp.). Activismo religioso conservador en Latinoamérica. Córdoba: Ferreyra-CDD, 2010.

42. VAGGIONE, J. M. Introducción. En: MORÁN FAÚNDES, J.M; SGRÓ RUATA, M.C.; VAGGIONE, J. M. (eds.) Sexualidades, desigualdades y derechos. Córdoba: Ciencia, Derecho y Sociedad/UNC, 2011.p. 13-55.

43. VERÓN, E. La semiosis social. Barcelona: Gedisa, 1993.

Recebido: 27.07.2015

Aceito: 02.03.2016 